\title{
Construction of Library Periodical Document Management Under Network Environment
}

\author{
Lili Zhao ${ }^{1, *}$ Lishu Zhang ${ }^{1}$ Dake Wang ${ }^{1}$ \\ ${ }^{1}$ Book Information Management Office, Aviation University of Air Force, Changchun, Jilin 130062, China \\ *Corresponding author. Email: 24929856@qq.com
}

\begin{abstract}
Under the network environment, the traditional books management model of journal literatures have been unable to adapt to the needs of the development of The Times, therefore, the librarian need to make full use of network technology to optimize the management structure of library periodicals and literature, innovate the management mode of library periodicals and literature, fully excavate valuable journal resources, use big data technology to understand readers' reading needs by analyzing their information, and do a good job in the integration of library collection resources and journal information science literature analysis.
\end{abstract}

Keywords: Network environment, Library, Periodical literature management.

\section{INTRODUCTION}

With the advent of the era of network, the library periodical literature management structure has also changed and electronic journal literature has launched. Document collection structure shows the characteristics of diversity, the electronic, print, and network literature coexist. In order to improve the library management quality of journal literatures, the librarian must restore work idea by using the scientific measurement and the management of books information, with the help of big data technology, valuable literature information is deeply mined to realize the organic integration of collection resources. In addition, libraries should pay attention to the professional training of librarians and constantly improve their literature management skills.

\section{REESTABLISHING THE WORKING CONCEPT AND IMPROVING THE PERIODICAL LITERATURE INFORMATION SYSTEM}

The librarian must set up a new service idea when dealing with the library periodical literature to assist the library and continuously improve the comprehensive service quality. By interpreting the periodical information and the reader information carefully, the librarian can meet the service demand of the readers through the information integration and analysis. At the same time, the librarian should make full use of big data system for unified management of library resources to improve the quality of the library's literature information service, and accurately input the specific location of the paper version of the literature on the shelf into the electronic version of the literature survey equipment, so as to facilitate readers to consult.

Under the background of network environment, librarians should assist the library to build a perfect periodical literature information system and set up periodical information database. Through comprehensively optimizing the structure of document resources allocation and constantly strengthening the construction of library information resources, librarians can promote different forms of periodicals for readers, and at the same time, allocate two-dimensional code, website and CD for paper books, so as to innovate the book carrier. On the other hand, librarians should reasonably control the proportion of traditional journal literature resources and electronic journals, so as to promote the perfect combination of the two, and do a good job in the information integration of the two journals. 


\section{USING THE SCIENTIFIC MEASUREMENT METHOD TO DO WELL THE PERIODICAL INFORMATION SCIENCE LITERATURE ANALYSIS}

As early as 1978, the National Academy of Sciences put forward the plan to implement the integration of library and information, advocating the organic integration of library and information resources, so as to realize the unified planning of the two resources and avoid the waste of resources. In 1978, the Chinese Academy of Sciences established the LIS Center, which led to the integration process of library and information management, and two academic terms, "LIS Integrated Management Model" and "Library and Information Science", came into being. Up to now, after more than 40 years of development, library and information science research has achieved gratifying results and accumulated valuable experience. At present, the term LIS has been widely used in academic circles and has been widely recognized by scholars.

Starting in the 1980s, scholars began to use "information management", "integration of book intelligence" and LIS for key words to write academic papers. Many institutions and universities have been founded by journal named "information". The LSE created the modern information technology, Jiangsu University created the books intelligence research. The library and information knowledge was established in Wuhan University, which further strengthened the connection between library document resource management and information science.

In a narrow sense, scientometrics is a subject that conducts quantitative research on science and has a history of more than one hundred years. From the perspective of development, China began to study scientometrics in 1965. In 1979, Mr. Zhao Hongzhou published the first paper on scientometrics in China titled "Research on the Social Age of Scientists". In 1980, he successfully constructed the "Mining Model of Scientific Discovery", which was then well received in the UK. Later, Liang Liming, Qiu Junping, Wu Yishan, Zhang Bihui, Jiang Guohua, Dong Ke, Ma Feng and other scholars all made great achievements in the field of scientometrics, and their academic research value was very high.

At present, the Chinese Academy of Sciences has established the Citation Index (CSSCI), and has used the index to accurately count the number of citations of books and literature. Combined with the number of articles, impact factors and expert opinions, the data of academic journals in the field of science are included in a targeted way. At present, many institutions use the data inside the database as an academic, disciplinary and institutional evaluation index. Secondly, many Chinese scholars regard CSSCI as a source of basic data for scientific research. From the perspective of overall structure, the periodicals derived from CSSCI mainly include Library Science Research, Journal of Information, Information Science, National Journal of Library Science, Information Theory and Practice, Information and Data Work, Books and Information, etc. The performance of periodicals is often simply written as "JP" in English, implying the performance ability of periodicals' contents. If JP is strong, it indicates that periodicals have a great influence in their respective fields; otherwise, it indicates that periodicals have a weak influence.

The measurement method of journal performance based on scientometrics has five indicators, namely QPP (number of articles published), IF (impact factor), TC (total number of cited papers), HCP (number of highly cited papers) and $\mathrm{H}$ ( $\mathrm{H}$ index of journals). QPP (quantity of articles) belongs to the information output of journals. In general, the more times and contents of information output, the greater the external influence. According to the survey, the three journals with the most output times in China are LSE, JIN and LWS. The types of journal articles are mainly papers. In the output journals, except LSE which is bimonthly, others are monthly or bimonthly. In addition, the average QPP based on scientometrics shows that among the bimonthly journals, the first one is LIB, and the least one is JTC. The average QPP quantity of most subjournals is about 25. In the work of impact factor analysis, the impact factor (IF) of the current year is usually the total number of the articles published in the previous two years of the journal divided by the total number of the articles published in the previous two years of the journal. It is generally widely used in the evaluation of academic journals. At present, JLS, JAL and JTC are the top three IF journals in China. According to the survey, the average IF of JLS founded by the Library Association of China and the National Library of China is higher than that of other periodicals, which indicates that JLS occupies an important position and absolute authority among Chinese periodicals. 
It should be noted that IF is not immutable, and the IF of each year is not absolutely stable. If the IF of the previous year is 1 , and the IF of last year is 2.078 , it means that the IF of last year is twice that of the previous year. Therefore, the average IF should be correctly adopted in the ranking.

\section{USING BIG DATA TECHNOLOGY TO DO A GOOD JOB IN THE INTEGRATION AND MINING OF COLLECTION RESOURCES}

In 2012, the United Nations announced that the world has entered the era of big data, and the big data technology is a new development achievement following information technology. The technology has $4 \mathrm{~V}$ characteristics, namely Volume (Mass Data Scale), Velocity (High Speed Flow of Data), Variety (Diversified Data Types) and Value (Large Data Value). At present, big data has become a methodology and a value which causing changes in human thinking and changes in various industries. Through analyzing and mining massive data, the huge product service system can be optimized and the in-depth cognition of the product can be strengthened. From the macro level, the transformation of human thinking in the era of big data is mainly reflected in the following three aspects: first, when analyzing data, humans no longer only rely on small sample data, but conduct in-depth analysis of all relevant data with the help of big data technology; Second, humans not only pursues the accuracy of micro data, but also pays attention to the insight of macro data; Third, humans not only pay attention to the traditional causal relationship, but also dialectically analyze all the relevant relationships and apply the analysis results to practical work. In addition, big data technology will apply advanced sensing equipment and super computing power to deep mining and accurate analysis of massive data in the real world, the virtual world and the virtual world combined with the real world, so as to make correct behavior judgments and make the best decisions.

For modern library management work of journal literatures, big data support literature resource manage system, information management system, the network periodical management system, and the interactive platform system, periodical literature information could transfer into digital information. What cannot be ignored is that in the process of literature information analysis and integration, it is necessary to use big data technology to mine valuable information from all kinds of data, build analysis technical model, and distinguish the relationship between literature and journal reading variables, so as to extract the most valuable data and information. For the journal literature information mining work, the data mining technology used in this work will comprehensively use artificial intelligence technology, mathematical statistics technology, machine learning technology method to analyze and process the original data. According to the analysis results, librarians set up a three-dimensional document data model. The model is used to analyze the relationship among the variables of journal literature information content, literature resources and readers' reading information, according to the number of journal literature clicks, borrowing and readers' information. Librarians analyze readers' reading needs and provide readers with the required journal documents according to the analysis results. The three-step process of data mining technology includes clustering, association rules and text mining. Data mining technology can present complete knowledge and recommend valuable journal literature. At the same time, librarians should make full use of big data technology to integrate all collection resources and promote collection structure into data information. Through the construction of multiple retrieval methods to achieve different disciplines and interdisciplinary literature collation work, and promote the literature management system upgrade. In addition, librarians can also use data analysis technology to comprehensively analyze massive data, and then, through modeling to understand the current journal literature management work potential problems, forecast the development of journal literature management work dynamic. The basic data of the literature data analysis technical model is the literature reading click data (including social software, mobile terminal, PLE, LMS, etc.), and the literature reading volume is evaluated through data collection and data analysis. Collect intelligent data, the so-called intelligent data includes journal download, literature borrowing and other data.

\section{DOING A GOOD JOB IN THE VOCATIONAL TRAINING OF LIBRARIANS}

Libraries should pay attention to the vocational training of all librarians, guide them to learn the knowledge and technology of periodical literature management under the network environment, and change the traditional working concept. The library should organize librarians to actively participate in 
outdoor learning activities, accumulate working experience, pay attention to innovation in daily work, and give full play to their potential and wisdom. When the library carries out the professional training of librarians in the network environment, it should pay attention to improve the training quality, develop the management workflow, and do well in management personnel training, the design of the periodical literature management training project, the organization and implementation of the training and the evaluation and feedback of the training. In addition, the librarian should not only pay attention to the theoretical knowledge and professional skills training of librarians, but also pay attention to strengthening their professional ethics training, guide them to establish the spirit of love and dedication and pioneering and innovative ideas, and actively adapt to the requirements of journal literature management under the network environment.

\section{CONCLUSION}

To sum up, based on the network environment, the librarian should optimize the management scheme of journal literatures by making full use of network technology and big data technology endeavor to realize the organic integration of periodical literature resources. By using scientific measurement, the librarian can do a good job of periodical information science literature analysis and constantly improve the management structure of journal literatures. In addition, the library should pay attention to the vocational training of all the librarians and cultivate the high-quality management team comprehensively.

\section{AUTHORS' CONTRIBUTIONS}

Lili Zhao is responsible for experimental design; Lishu Zhang collects data; Dake Wang has contributed to revising and editing.

\section{REFERENCES}

[1] Yan Wen. Discussion on Library Periodical Literature Management in Network Environment $[\mathrm{J}]$. Office Business, 2018(09):161.

[2] Qun Feng. Discussion on Library Periodicals Management Mode under Network Environment [J]. Modern State-owned Enterprise Research, 2019(04):173.
[3] Xingge Zhang. On the service innovation of public library in the era of "Internet $+"[\mathrm{~J}]$. Journal of Zhengzhou Institute of Light Industry (Social Science Edition), 2016, 17(1):31-36.

[4] Weiran Zhang. Discussion on Public Library Reading Promotion Service in the "Internet +" Era [J]. Library Research and Work, 2018(1):65-68

[5] Youfei Huang. Analysis on the Utilization of Digital Resources in Vocational College Libraries [J]. Information and Data Service, 2014(09).

[6] Jiejie Duan. Reflections on the Innovation of Library Periodical Management Mode in the Information Age [J]. Cultural and Educational Data, 2018(32). 